\title{
Review of experiments and calculation procedures for ship collision and grounding damage
}

Liu, Bin; Pedersen, Preben Terndrup; Zhu, Ling; Zhang, Shengming

Published in:

Marine Structures

Link to article, DOI:

10.1016/j.marstruc.2018.01.008

Publication date:

2018

Document Version

Peer reviewed version

Link back to DTU Orbit

Citation (APA):

Liu, B., Pedersen, P. T., Zhu, L., \& Zhang, S. (2018). Review of experiments and calculation procedures for ship collision and grounding damage. Marine Structures, 59, 105-121. https://doi.org/10.1016/j.marstruc.2018.01.008

\section{General rights}

Copyright and moral rights for the publications made accessible in the public portal are retained by the authors and/or other copyright owners and it is a condition of accessing publications that users recognise and abide by the legal requirements associated with these rights.

- Users may download and print one copy of any publication from the public portal for the purpose of private study or research.

- You may not further distribute the material or use it for any profit-making activity or commercial gain

- You may freely distribute the URL identifying the publication in the public portal 


\title{
Review of collision experiments and calculation procedures for ship structural damage
}

Bin Liu ${ }^{\mathrm{a}, *}$, Preben Terndrup Pedersen ${ }^{\mathrm{b}}$, Ling Zhu ${ }^{\mathrm{a}}$, Shengming Zhang ${ }^{\mathrm{c}}$

a Key Laboratory of High Performance Ship Technology of Ministry of Education, School of Transportation, Wuhan University of Technology, Wuhan 430063, China.

b Department of Mechanical Engineering, Technical University of Denmark, Lyngby DK-2800, Denmark.

c Global Technology Centre, Lloyd’s Register EMEA, Southampton S016-7QF, United Kingdom.

* Corresponding author: liubin8502@whut.edu.cn

\begin{abstract}
The paper presents a review of experiments and calculation procedures for the resistances of ship structural components subjected to impact loadings. The purpose of the paper is to highlight the importance of large-scale collision and grounding experiments and to discuss the technical difficulties and challenges in analytical, empirical and numerical analyses. Experiments on ship structural components are benchmarks and baselines, used to propose analytical or empirical formulae for the structural energy absorptions and/or to validate numerical analyses considering the actual structural and material characteristics. In recent literature, analytical and numerical calculations provide relatively accurate prediction of purely plastic responses of ship structures under impact loads, but universal approaches have not been found for fracture predictions. Most of the proposed formulae for failure criteria have their dedicated scope of application, and all approaches have shown limitations when evaluating material fractures in various collision scenarios. Recently, semi-analytical approaches have been developed to evaluate the relationship between the absorbed energy and the damaged material volume, taking into account the structural arrangements. It seems that these semi-analytical methods often show better accuracy than the numerical simulations when predicting the experimental results.
\end{abstract}




\section{Keywords}

Ship structure; Ship collision; Experiment; Numerical simulation; Analytical method; Review.

\section{Introduction}

A review paper [1] on ship collision and grounding analysis procedures advocating for standards for design against accidents was published in 2010 and the paper emphasizes that procedures should be developed to increase the crashworthiness of ship structures in order to reduce the high economic, environmental and human costs associated with ship collisions and grounding. In evaluation of collision and grounding events, one of the key issues is an accurate prediction of the damage extent of ship structures. The main focus of the present paper is to review the literature on experiments and calculation procedures for the internal mechanics of ship collisions and to propose further research topics.

The evaluation methods for internal impact mechanics include experiments, empirical formulae, analytical methods and finite element simulations. Their advantages and disadvantages are summarised in Table 1, and the analysis procedure for impact strength of ship structural components are presented in Fig. 1. Two decades ago, a potential design procedure for grounding and collision was proposed by Amdahl et al. [2]. Ship grounding was categorized as two types: vertical penetration referred to as "stranding" and horizontal sliding referred to as "raking"; the internal mechanics of ship collision was also separated into two types: side penetration referred to as "side collision” and bow crushing in head-on collision referred to as "bow collision".

In the literature, the investigated ship structural components include plates, stiffened panels, web girders, web and stringer intersections, stiffened decks, single bottoms, double-hull sides and bottoms, straight bows, bulbous bows, etc. The failure modes associated with internal mechanics of ship collision and grounding can be described by plate tension, folding/crushing, tearing/cutting, and sliding, etc. The failure modes involved in ship side collision, bow collision, stranding and raking are summarised in Table 2. 
Full-scale ship collision and grounding experiments are extremely expensive and thus rarely conducted. Real life accidents are influenced by many components and unknown variables and consequently difficult to analyse in detail. However, damage and failure patterns from collision accidents provide the true pictures in revealing the ship damage mechanisms. Fig. 2 shows examples of recent collision accidents. It is fundamentally important to consider actual ship collision scenarios and ship structural scantlings and arrangements when conducting laboratory collision tests.

Large-scale laboratory tests are the most practical means for investigating the crashworthiness of ship structures and providing data for calibrating analysis procedures. In impact studies of ship structures, quasi-static loads are most often used in the investigations on the experimental impact responses. This is a valid simplification because ship collisions normally occur at low velocities that only affect slightly the local structural response characteristics.

A ship is conveniently viewed as an assembly of plated structures where the involved damage mechanisms of structural components can be added up to evaluate the impact strength of whole ship structures. Hence, a series of structural components have in the past been selected to examine experimentally their primary deformation modes and damage mechanisms. These experiments on structural components are mainly used to propose empirical or analytical formulae for the structural energy absorptions and/or to validate numerical analyses considering the actual structural and material characteristics. However, the interactions between components could be very important and too simple model tests may miss some critical factors affecting the results.

Analytical and empirical methods remain the most rapid tools for evaluating the crashworthiness of ship structures. A considerable amount of the recent work is based on the upper bound theorem of plasticity and is focused on the proposition of simplified analytical methods to evaluate the structural plastic deformation, reaction force and energy dissipation. The analytical methods developed from plastic mechanism analysis can reveal the main features of the structural plastic deformation characteristics during the impact. These methods can establish the global 
pattern of deformation by adding up all local contributions of the individual structural components and they are capable of capturing the main features of the mechanical damage. Various analytical formulae have been proposed to evaluate the energy dissipation of relatively complex structures, such as stiffened plates, web girders and plate intersections. Nevertheless, the material failure is still an issue for theoretical analysis of complex structures. For this reason, simple empirical and semianalytical formulae for evaluating the relationship between the absorbed energy and the damaged material volume are widely used for ship collision and grounding analyses in the marine industry due to their simplicity and relatively good accuracy.

More recent comparisons with experiments are made with finite element simulations. The wide spread application of finite element numerical simulations has been used to predict the plastic deformation of ship structures. The failure due to material rupture in welded ship structures is still not well resolved numerically. Failure strain and crack propagation are highly dependent on the size of the finite elements, and the criteria for initiation of ductile fracture are still not well established. The stress triaxiality controls the initiation of the ductile fracture in virgin plates [5]. Moreover, a rather coarse mesh is required for the numerical simulation of ship structures. The strain rate effect is often omitted due to the relatively low striking velocity. Although various failure criteria involving the mesh size sensitivity have been proposed, it is difficult to find a universal criterion to evaluate all the existing experiments. At present these criteria are validated against their selected experiments and therefore the existing fracture criteria should be applied in association with these specific collision scenarios. A further complication is the effect of the discontinuities and imperfections caused by the welded connections.

This paper summarises the literature on large-scale collision experiments and reviews experimental, numerical and analytical works on the energy absorption of ship structural components under impact loadings. The review comments on the advantages and disadvantages of various existing analytical methods, and recommends the most appropriate method to assess each collision scenario. 


\section{Large-scale experiments}

Structural model tests are the most practical means for evaluation of analysis procedures for investigation of the crashworthiness of ship structures. The large-scale experiments require the use of expensive test facilities and equipments in order to capture the entire impact event. In most studies of crashworthiness of ship structures subjected to lateral collision loads, the experiments have been conducted in a quasi-static manner. The experiments provide the force-displacement responses and the failure modes of the impacted structures. The primary energy absorbing mechanisms of published experiments are summarised as follows.

- Membrane deformation and penetration of stiffened panels in side collision or stranding [6-18]

- Compressed folding deformation and concertina tearing of web girders in side collision or stranding [19-25]

- $\quad$ Penetration and crushing of double hulls in side collision or stranding [26-39]

- Concertina tearing and cutting of stiffened panels in raking [25, 40-47]

- $\quad$ Cutting of double hulls in raking [45, 48-51]

- Axial crushing of basic L, T and X type elements in bow collision [52-55]

- Crushing of bulbs in bow collision [51, 56-62]

\subsection{Side collision and bottom stranding}

Stiffened panels, web girders and double-hull structures are the main components of ship sides and bottoms. In side collision and bottom stranding (e.g. vertical deformation) scenarios, the exposed ship structural components are dented or penetrated by striking ships or seabed obstructions. The struck structural components experience similar failure patterns, and therefore they are summarised and reviewed together.

\subsubsection{Stiffened panels}

Stiffened panels represent the single skin ship side and single bottom structures and the outer panels of double side shells and double bottom structures. Recently, some experimental works were 
performed on stiffened panels struck by wedge indenters [7, 8, 10, 11]. The described collision scenario was one where a rigid bulbous or a knife edge shaped straight bow impacts at a side panel unit limited by one span between the web frames and the stringers. The stiffened panel ruptures initially at the end corners of the wedge indenters, and afterwards the cracks propagate perpendicularly and centrally, as shown in Fig. 3(a). The stiffened panels lose their capacity to sustain the impact load when the plates are completely cut by the wedge indenters. The nose of bulbous bow is sometimes simplified as a hemisphere, and thus hemispherical indenters are also used to strike the stiffened panels in the experiments described in Refs. [9, 12, 14]. The stiffened panels deform plastically due to the membrane forces, and afterwards cracks are initiated at the necking circle or around lateral stiffening, see Fig. 3(b).

In ship stranding, the bottom suffers similar failure modes as with side impact. The stranding experiments usually apply a rigid cone indenter with a hemispherical nose to punch the scaled ship structures [6]. The stiffened panels rupture along the stiffener underneath the indenter. The experimental results are very sensitive to the geometry of the indenter, particularly the reaction force decreases with the contact area since the panels can experience smaller local indentation. This localised contact provokes easier rupture of the stiffened panels and fails at a smaller displacement and force.

Generally, the experiments on stiffened panels can only represent minor collision accidents, since the energy absorptions of stiffened panels are relatively small comparing with the mean striking energy of collision accidents. For improving ship safety against collision, novel crashworthy ship side structures, such as corrugated panel with 'U-shaped' stiffeners, sandwich panel with oblique webs or with multiple 'X-shaped' cores, have been developed and tested in relatively large scale showing higher energy absorption capabilities compared to the conventional ship side structures [15-18]. 


\subsubsection{Web girders}

Web girders are the main structural forms of web frames and stringers in the double-hull ship sides and bottoms. Experiments have been conducted on the crushing resistance of web girders under local in-plane loads [19-24], see Fig. 4(a). The web girder mainly undergoes plastic compressed folding deformation, and its deformation is divided into two parts, plastic deformation and elastic buckling zones [63]. A complete fold is formed at a certain penetration and the fold is fully compressed with further loading.

For web girders stiffened longitudinally (i.e. the stiffeners are perpendicular to the direction of the incoming striker), the crushing resistance is very close to that of unstiffened web girders [21, 63]. On the other hand, when the web girders in side shells and bottom floors are stiffened transversely they can sustain larger crushing forces during ship side collisions and strandings since the transverse stiffeners crush axially. This was demonstrated by Liu and Guedes Soares [24] who analysed experimentally the crushing resistance of transversely stiffened web girders.

The concertina tearing mode can be considered as the web crushing with rupture at the two end supports, see Fig. 4(b). Wierzbicki [25] and Simonsen and Ocakli [22] conducted experiments to analyse the mean wedge pushing force required to produce the concertina tearing failure mode.

\subsubsection{Double-hull structures}

Stiffened panels and web girders are the main structural elements which compose double-hull structures. In the damage mechanisms of double-hull structures, the outer plate mainly suffers local denting and crack initiation and propagation, while the web frames experience plastic buckling and progressive crushing and even cutting, see Fig. 5.

Four decades ago, a series of static and dynamic collision model tests were conducted in Japan and Germany to analyse the various aspects of the impact problems, such as the design of ship side structures and the effect of striking bow shapes [26, 27]. Afterwards, Ito et al. [28] conducted a series of experiments with double-sided hulls struck by raked and bulbous bows, and the collision scenarios were grouped into five categories based on different impact locations. 
In 1990s, a series of full-scale ship collision experiments was carried out by the TNO in Netherlands [31, 32, 35, 36], using two inland waterway tankers with length of about $80 \mathrm{~m}$. The striking bow was specifically made and it was a relatively hard bulb. The impacted structures were installed in the middle of the struck ship and their dimensions were based on conventional and newly developed double-hull tanker side structures. These are probably the most complicated collision tests ever carried out. Illustration of the collision tests and a damaged model after test is shown in Fig. 6 [35].

Recently, Karlsson et al. [37] conducted an experiment of scaled double-hull ship structures under a hemispherical indenter. The indenter was located centrally at a plate-stiffener intersection. Tautz et al. [39] reported collision experiments of rigid and deformable bulbous bows driven against double hull side structures and found that the stiffness of the striking vessel has noticeable influence on the distribution of collision energy.

In the analysis of bottom stranding, Arita and Aoki [29] and Amdahl and Kavlie [30] performed model tests of a double hull penetrated by a rigid cone indenter, investigating the structural local deformations. Afterwards, Paik et al. [33] and Wang et al. [34] conducted experiments of a conventional double bottom on a conical rock, evaluating the energy absorption and fracture initiation of double hulls for different structural arrangements and bow forms. The failure modes differ when loading at a bare plate and at a plate intersection. The initial crack occurs in the contact area when penetrated by small radius indenters, whereas the crack initiates at the plate-web intersections when penetrated by large radius indenters.

\subsection{Bottom raking}

Bottom structures subjected to horizontal grounding forces are scratched or torn by protruding obstructions of the seabed. Thus, instead of denting and penetrating as in bottom stranding, the bottom structures in raking scenarios suffer scratching and tearing involving the effects of friction, plasticity and fracture, as shown in Fig. 7. The mostly investigated bottom structural components subjected to bottom raking are stiffened panel components and double-hull structures. 
The concertina tearing presented in Fig. 4(b) is a possible failure mode of ship bottoms striking a rock or reef in a grounding accidents [25], and another failure mode of bottom raking is plate cutting. Paik [44] performed a series of cutting tests on longitudinally stiffened plates in quasistatic loading. Simonsen and Tornqvist [47] investigated experimentally crack propagations in large-scale shell structures under in-plane bending and stretching (or uniform stretching).

For raking of double-hull structures, Kuroiwa et al. [45] investigated a situation where a rigid wedge indenter penetrates quasi-statically into the structure. In order to investigate grounding of a ship bottom structure on a pinnacle rock, Rodd [48] conducted grounding tests of a 1:5 scaled oil tanker structures. The ship bottom test specimen was mounted to a railway car and run over an artificial rock which was connected to vertical and horizontal load cells. Sterndorff and Pedersen [49] performed a series of large-scale ship grounding experiments on an artificial island to analyse the hull girder response of ships running aground. From 1994 to 1995, a series of Japanese ASISsponsored grounding experiments was carried out in the Netherlands to simulate grounding of a 1:4 scaled VLCC (Very Large Crude Carrier) [50], and illustration of the tests is presented in Fig. 8. Recently, Calle et al. [51] performed an experiment of a 1:100 scaled ship bottom structures launched against a rigid sharp indenter. The fracture of ship bottom structures is dominated by tearing failure of the external plate and internal transversal reinforcements with a negligible reduction of the plate thickness.

\subsection{Bow collisions}

Axial crushing of basic L, T and $\mathrm{X}$ type elements was investigated experimentally in order to analyse the bow crushing mechanics [52-55]. These elements are the main structural components in longitudinally stiffened ship bows.

Amdahl [56] performed six model tests on straight bow crushing, presenting diagrams of compressive load versus end shortening. Hagiwara et al. [57] performed experiments of a 1:5 scaled bow model of a cargo ship (typical small ship) and a 1:10 scaled bow model of an oil tanker (typical large ship) to investigate the resistance of the bows. These two bow models were stiffened 
transversely, omitting the longitudinal stiffeners in the inner structures. As a bulb is most often is a part of a normal ship bow, a series of quasi-static experiments were carried out to analyse the axial crushing of bulbous and blunt-shaped bows in right-angled collisions [58-60, 62], see Fig. 9. The designed bows are stiffened longitudinally and/or transversely. The scaled bows were crushed axially by rigid walls, and the force-displacement response and the collapse modes were recorded. Afterwards, Yamada and Endo [61] conducted experiments on scaled bulbous bows to investigate also the bending collapse of the bulbous bow structures in oblique collisions.

Recently, Calle et al. [51] performed an experiment of a 1:100 scaled bulbous bow structures launched against a rigid wall. The axial crushing shows a complete inward folding of the first ring section of the stiffened bulbous bow. This folding is composed by small folds around and between the outer plate and the first ring reinforcement.

\subsection{Comments on scaled experiments}

The testing of scaled models is indispensable to study the resistance characteristics of complex structures. Larger-scale experiments will represent more closely realistic welded ship structures and reflect effects such as: (1) mechanical material properties are altered in the weld heat-affected zone; (2) weld throats provide additional thickness improving structural strengthening; (3) residual stresses exist around the welding; (4) the weld smoothes the transverse transition in the plate intersections. These phenomena induced by welding play an important role to represent better the failure patterns of actual ship structures. In addition, the welding can provide additional strength and rotational stiffness in the weld joints delaying the tripping and folding of lateral stiffening and provoke strain concentration and fracture in the heat-affected zone around the stiffening. Nevertheless, these phenomena are usually omitted in the numerical and analytical analyses of ship structures.

The results obtained from experiments of scaled models provide understanding of the damage mechanics of geometrically similar full-scale prototypes. However, the relationship between scaled models and the full-scale prototypes is very complex due to the scaling effects. 
Jones [65], Liu et al. [11] and Oshiro et al. [66] commented on the similarity complications in experiments, especially for material fracture and strain rate effect.

When the structural behaviour involves little or no fracture, the results of the scaled model can be extrapolated to the full-scale prototype according to the elementary scaling principles, provided that the strain rate sensitivity of the material can be ignored [65]. On the other hand, when fracture occurs in complex structures, especially in structures suffering shear failure, the scaling is much more complicated [67]. The scaling laws for material rupture are still not well resolved. Moreover, the phenomenon of structural crack propagation does not scale according to the same principles which govern geometrically similarity scaling [65], and so far, there are no techniques available to extrapolate the fracture process of scaled models to full-scale prototypes. Therefore, it is recommended to conduct large-scale experiments in order to reduce the scaling effects.

\section{Analytical and empirical methods}

The main purpose of experimental studies on impact strength of ship structural components has been to derive and verify analytical and empirical expressions for evaluating the structural energy absorbing mechanisms and failures.

Simplified analytical methods have been derived to analyse the plastic collapse mechanisms of individual structural members for assessing the energy absorption of ship structures. The response of complex marine structures has then been estimated as a sum of the crushing loads of the structural components. For the pure plastic crushing modes without fracture the simplified methods are based on the upper bound theorem of plasticity, where kinematically admissible collapse patterns are applied to find the collapse load. The upper bound theorem is considered sufficient to model many complex problems in ship collisions and grounding [23, 64]. For these theoretical analyses, the most important step is to accurately express the identified deformation modes of the structural elements.

Besides the pure plastic deformation modes researchers of the last few decades have identified the major failure patterns for structural components in ship's collision and grounding 
which include fracture, such as plate tension, folding/crushing, tearing/cutting and concertina tearing $[23,68,69]$.

\subsection{Analytical methods}

Analytical methods for evaluating the resistance of ship structural components have been investigated extensively.

\subsubsection{Side collision and bottom stranding}

Haris and Amdahl [70] proposed an analytical model to assess the resistance of a ship side during a collision, dividing the ship structure into a shell plating, cruciforms and web girders. An analytical formula to calculate the strength of shell plating was proposed, while the resistance of cruciforms and web girders were evaluated analytically by the methods of Hayduk and Wierzbicki [52] and Zhang [23], respectively. In the literature, more analytical analyses of the crushing resistance of plates [68, 71-76], stiffened panels [7, 11, 77], cruciforms [55, 56, 78, 79] and web girders [22, 23, 80-82] were reported and a comparison of the accuracies of these analytical methods can be found in Refs. [11, 63, 81, 83, 84]. Liu and Guedes Soares [85] presented an analytical method to examine the energy absorbing mechanisms of double-hull ship structures subjected to a flat edge indenter, based on the theoretical investigations on stiffened panels [11] and web girders [63], see Fig. 10.

For ship bottom stranding, the structural damage mechanisms are similar to those of side collisions. Therefore, the analytical methods for evaluating the ship side collisions can be applied in the assessment of bottom stranding. The difference could be the simplification of the geometry of the striker, since the seabed shape is different from bow shapes.

\subsubsection{Bottom raking}

The seabed topologies have been categorized in the grounding scenarios studied by Amdahl et al. [2], as 'rock', 'reef' and 'shoal'. The grounding over rock or reef has been analysed in Refs. [86-89], and the assumed deformation mode of bottom plate in raking is shown in Fig. 11. 
Initially, Wang et al. [86] developed a simple method to predict the grounding strength of ships, assuming that the grounded ship moves in the horizontal plane, without pitching or heaving movements. Four primary failure modes were proposed: the stretching failure of transverse structures, denting, tearing and concertina tearing failure of bottom plates. The calculation formulae for these identified failure modes are assembled to construct a prediction method for bottom strength. Simonsen $[87,88]$ presented a set of analytical expressions which can be used to calculate the reaction force on a ship bottom deformed by a conical rock with a rounded tip, and the resistance of outer and inner bottom plating, bulkheads, longitudinals, web frames, girders and floors were evaluated. Zhu et al. [89] studied the damage extents of grounded ships and assessed two real life grounding accidents. Afterwards, Heinvee et al. [90] derived a simple formula based on small number of parameters that describe the structural resistance of a tanker in a grounding accident. In the literature, more analytical analyses were reported on the plate cutting and tearing which are the main damage mechanics of grounding over rocks or reefs [40, 47, 91-94].

Hong and Amdahl [95] proposed a rapid assessment procedure for ship bottom structures subjected to shoal grounding. The proposed simple method is established on the basis of the primary deformation modes for the major bottom structural members, i.e. sliding deformation of longitudinal girders [96], denting and crushing of transverse members [81] and indentation of bottom plating. As the method developed by Hong and Amdahl [95] does not consider the stiffeners in double bottom, Yu et al. [97] investigated analytically the predictions of structural performance of stiffened double bottom during ship shoal grounding.

\subsubsection{Bow collision}

Formulae for estimating axial crushing forces of L, T and X type elements and bow structures have been proposed in Refs. [23, 53-56, 59, 68, 78, 79, 98-104]. An assumed deformation mode of a bulbous bow under crushing is shown in Fig. 12. Paik and Wierzbicki [102] performed a comprehensive benchmark study on the application of simplified methods to crushing tests of plated structures, comparing the analytical methods proposed by Amdahl [56], Wierzbicki and 
Abramowicz [98], Abramowicz [100] and Paik and Pedersen [101] with experimental results. It was concluded that the methods by Wierzbicki and Abramowicz [98] and Paik and Pedersen [101] give relatively good estimations for axially compressed plated structures.

Recently, Zhang [23], Yamada and Endo [59] and Zhang et al. [103] developed a new set of simplified analytical methods for analysis of plate crushing and ship bow damage in head-on collisions. Yamada and Pedersen [104] reviewed and estimated analytically the axial crushing of bulbous bows, showing that Yang and Caldwell [78] gives the best predictions of the experimental crushing forces.

Based on procedures developed by Amdahl [56] and Yang and Caldwell [78] empirical expressions for bow load-penetration relations was presented in Ref. [99] for ice strengthened commercial ships. These empirical bow collision forces are now part of Eurocode - Action on Structures.

\subsection{Empirical and semi-analytical methods}

Minorsky [105] developed the well-known empirical formula $(E=47.2 R+32.7)$, which relates the absorbed energy ( $E$ in $\mathrm{MJ}$ ) to the destroyed material volume $\left(R\right.$ in $\left.\mathrm{m}^{3}\right)$. Although its limitations have been well recognised, this empirical formula has been widely used in ship collision and grounding analyses in the industry because of its simplicity and also partially due to the fact that no other fully recognised simple alternative methods were available or that some alternative potential methods need more validations and verifications in order to establish the necessary confidence and recognition.

Based on Minorsky's concept, semi-analytical methods for the absorb energy and the destroyed material volume, taking into account the structural arrangements, the material properties and the damage patterns was established in Ref. [106]. This method was validated against a large number of existing experimental results and detailed numerical results. The accuracy of the simplified method was further demonstrated and proven in Ref. [3] with 20 quality model tests from 
the public literature (absolute deviations $<10 \%$ ), see Fig. 13. The proposed formulae are presented as follows:

$E_{1}=0.77 \varepsilon_{\mathrm{f}} \sigma_{0} R_{1}$

$E_{2}=3.50\left(\frac{t}{b}\right)^{0.67} \sigma_{0} R_{2}$

$E_{\text {total }}=\sum E_{1}+\sum E_{2}$

where $E_{1}$ is the energy absorbed by the plastic tension damage mode, $E_{2}$ is the energy absorbed by the crushing and folding damage mode, $E_{\text {total }}$ is the total absorbed energy, $\sigma_{0}$ is the flow stress of the material, $\varepsilon_{\mathrm{f}}$ is the rupture strain of the material, $R_{1}$ is the material volume of the damaged/ruptured structural members in tension mode, $t$ is the thickness of the crushed plate, $b$ is the width of the plate in the crushed cross section and $R_{2}$ is the material volume of the crushed structural member. One of the important factors in using this approach is that the damaged spaces in heavy collisions is assumed to be the same as the contour of the penetrated rigid bow of the striking vessel and the material properties including the rupture strain can be taken from the standard coupon tensile tests.

The Guidance Notes for Collision Assessment for the Location of Low-flashpoint Fuel Tanks [107] recommend the above mentioned semi-analytical method to estimate the energy absorbed by destroying ship structural members in tension and crushing modes.

\subsection{Concluding remarks}

Although the analytical and empirical methods omit some factors in the actual structures, such as the welding effects, they provide fast and relatively accurate approaches to evaluate the structural crashworthiness in the preliminary design of ships.

In general, the simplified analytical methods based on the upper bound theorem of plasticity deal well with the prediction of collapse loads during the deformation process. Unfortunately, these analytical methods are less accurate when it comes to evaluate the initiation of material fracture during impact. In this case, empirical formulae or semi-analytical methods for assessing the absorbed energy related to the structural damages can be recommended. 


\section{Numerical simulations}

Finite element analysis of the structural consequences of ship collisions and grounding events is especially demanding to reveal the deformation and fracture process for two reasons. Firstly, the loads are such that the response behaviour of the structure is found to be quite nonlinear. Secondly, the finite element model has to be very large with extremely many elements since the complicated ship hull structure needs to be modelled in some detail. Owing to the computational resources there is an upper limit on the number of elements which can be used. The result is quite large sized finite elements compared to the dimensions of the scantlings of the ship structure.

Four types of nonlinearity are important for a consistent and comprehensive modelling of the crushing process in an accidental ship impact:

1. Material nonlinearity, for example the elastic-plastic behaviour of the steel material in tension or bending.

2. Geometrical nonlinearity caused by buckling and/or crushing of structural elements subjected to shear and compression and also the stiffening effect due to membrane stretching of for example laterally loaded shell plating.

3. Fracture and cracking of the material taking into account welds and imperfections.

4. Contacts between structural elements.

Furthermore, in the numerical modelling of ship structural strength components the effect of some aspects of the boundary conditions and the joining details are poorly understood.

\subsection{Material nonlinearities}

The nonlinear behaviour of the material includes plastic strain hardening and fracture strain. Commonly, the mechanical properties of the material are determined by tensile tests. Hence, the true stress-strain relationship is obtained from the recorded engineering stress-strain data in a simple or 'modified' power law form [108-111], or by combining the logarithmic flow stress curve until the onset of necking followed by a simple power law relation beyond localisation [112, 113]. It should be mentioned that very accurate flow material curves can be obtained by using optical 
systems that record the strain to failure in a uniaxial tensile test $[114,115]$. Unfortunately, most structural analysts do not have tensile test data to define the flow stress curve as input into their finite element codes [116]. Recently, Storheim and Amdahl [117] discussed the sensitivity of material strain hardening in finite element analysis of ship collisions.

In fact, the information available from standard material tests only includes the yield stress, the ultimate tensile stress and the engineering fracture strain [118]. Liu et al. [84] proposed simplified formulae to define the true material curve. The strength coefficient $(K)$ and the strain hardening exponent ( $n$ ) is determined by Eqs. (4) and (5) when the yield stress $\left(\sigma_{\mathrm{y}}\right)$ and the ultimate tensile strength $\left(\sigma_{\text {uts }}\right)$ are known:

$\sigma_{y}=K \cdot 0.006^{n}$

$\sigma_{u t s}(1+n)=K[\ln (1+n)]^{n}$

Later, the true stress is determined by the power law relation $\sigma_{\mathrm{t}}=K \varepsilon_{\mathrm{t}}{ }^{n}$ when $\varepsilon_{\mathrm{t}}>0.006$. It is dedicated to enhance the industry practice in collision simulations of ship structures when only limited time and material data are available.

For the evaluation of true fracture strain, Calle and Alves [119] presented a review on failure criteria used in finite element modelling of ship collision events.

Some semi-analytical equations, including the 'simple strain-state-independent' [35, 84, 120] and 'advanced strain-state-dependent' [121-123] criteria, have been proposed to obtain the practical failure strain for shell elements determined by element size and plate thickness. Ehlers et al. [124], Storheim et al. [125] and Marinatos and Samuelides [126] compared the accuracy of existing fracture criteria based on the simulations of experiments. They found large discrepancies among them. Although much effort has been made by investigators, the scatter of the results between finite element analyses and experiments using various suggested fracture criteria is still very large (see Fig. 14). 


\subsection{Boundary conditions}

Boundary conditions are an important aspect in finite element analysis. While standard boundary conditions for simply supported or fully clamped specimens are easy to implement in both analytical and numerical models, it is quite often difficult to reproduce them exactly in the experiments. This has been demonstrated in experimental investigations on the boundary conditions of laterally loaded specimens [127-129]. Usually, there are two support conditions applied in the experiments: bolting or welding, as shown in Fig. 15. For the specimens clamped by bolts, the axial sliding between the specimen and the supports can occur because of the mounting tolerance between the holes and the bolts. The specimens welded on the rectangular cross-section tubes could better simulate the fully clamped conditions assuming the supporting frames are rigid enough.

In general, the experimental tests cannot satisfy precisely the zero out-of-plane and in-plane displacement condition at the supports. The load capacity of a structure is strongly dependent on the axial restraint provided at the supports. Therefore, when developing numerical models that are to be compared with experimental results, it is necessary that the model represents the real boundary conditions, instead of the ideal ones that are the intention in the experimental programme. The modelling of experimental restraints should be defined adequately for each particular experiment.

\subsection{Joining details}

Many types of end connections are difficult to characterise accurately, particularly when acknowledging the effect of the manufacturing process [116]. The influence of weld joints on structural resistances was demonstrated numerically by Alsos et al. [130] and Liu and Guedes Soares [24]. The modelling of the weld joints is shown in Fig. 16. In order to account for the additional thickness caused by the weld seams, solid models can be easily created on the basis of the realistic weld shape. For the shell models, the plate thickness should be increased in the platestiffener intersection. The modelling of the weld joints affects the behaviour of the stiffeners, and also the prediction of the onset of fracture in the plate-stiffener intersection. 


\subsection{Comments on analytical methods validated by finite element simulations}

Before initiation of fracture the plastic deformation of ship structures subjected to a rigid indenter can be predicted well by the numerical simulations, and numerical simulations have been conducted to validate the simplified analytical methods [70, 95, 97, 131-133]. For example, Hong and Amdahl [95] proposed and validated a simple method for the rapid assessment of ship bottom structures subjected to grounding over seabed obstructions with large contact surfaces. As this type of complex collision and grounding experiments are difficult to conduct, the numerical simulations provide the only possibility for verification.

On the other hand, for the analysis of ship collisions involving material fracture the numerical simulation results do not yet have the desired accuracy and in those cases validation of simulation procedures as well as the analytical procedures by experimental tests are in demand.

\section{Conclusions and further work}

This paper reviewed experiments and calculation procedures for the resistance of ship structural components subjected to impact loadings. Comments are offered on the technical difficulties in interpreting numerical simulations, analytical and empirical calculations. It is observed that the availability of experimental results is needed for the further development of calculation procedures when fracture plays a significant role.

For experimental testing of structural components the establishment of relevant boundary conditions constitute a challenge. Most experimental supports are designed to simulate the fully clamped conditions, but it is difficult to reproduce such conditions exactly in the experiments, i.e. to design supports with so large stiffness that they ensure almost zero displacement boundary conditions. As the primary purpose of most experiments is to validate numerical and analytical analysis procedures, the influence of boundaries should be accounted for when evaluating the structural characteristics.

Various analytical approaches have been proposed to evaluate collision scenarios involving plastic deformation processes, but many aspects of the material fracture are poorly understood. In 
the analysis of ship bottom raking, some analytical equations have been developed for the cutting of a plate by a rigid wedge. Nevertheless, for other types of crack propagations, such as plate perforation, reliable theoretical solutions are lacking. Instead, semi-analytical methods have been proposed to assess the energy dissipation due to tension and crushing failures of structural members during collision accidents.

Explicit finite element analysis procedures can handle complicate nonlinear geometrical and material nonlinearities. In the numerical modelling of ship structural components, some aspects of the material plastic strain hardening, the boundary conditions and the joining details have been given much attention. Although various failure criteria have been proposed the problems of the prediction of material fracture strain are not solved with sufficient accuracy.

Generally, the evaluation of material fracture is the critical issue in the development of analytical and numerical approaches. There is a strong need to conduct more experiments to capture the phenomena of crack initiation and propagation in typical ship collision scenarios, which can provide the background for new development and validations of analytical and numerical methods. Another important issue is to accurately quantify the contribution of friction in collisions and grounding.

A logical future goal for research within this area should be to develop robust design criteria for the crashworthiness of ship structures such that also the most important Accidental Limit States (ALS), which includes collisions and groundings, can be included into the future classification rules for ships.

A first small step has been the Lloyd's Register Guidance Notes for Collision Assessment for the Location of Low-flashpoint Fuel Tanks. The development of these guidance notes clearly shows the advantages of moving towards limit state design. 


\section{Acknowledgments}

The work is supported by "the Fundamental Research Funds for the Central Universities (WUT: 2017II04XZ)". The views expressed in this paper are those of the authors, and are not necessarily those of Lloyd's Register.

\section{References}

[1] Pedersen PT. Review and application of ship collision and grounding analysis procedures. Mar Struct 2010;23(3):241-262.

[2] Amdahl J, Kavlie D, Johansen A. Tanker grounding resistance. In Proc. 6th International Symposium on Practical Design of Ships and Mobile Unit (PRADS1995): Seoul, Korea 1995; vol. 2: p: 1072-1083.

[3] Zhang S, Pedersen PT. A method for ship collision damage and energy absorption analysis and its validation. Ships Offshore Struct 2017;12(sup1):S11-S20.

[4] Martens I. Konstruktive Aspekte beim Entwurf von Bugwülsten zur Verbesserung des Energieaufnahmevermogens bei Schiffskollisionen (In German). Ph.D. Thesis, Technical University of Hamburg, 2014.

[5] Wierzbicki T, Bao Y, Lee YW, Bai Y. Calibration and evaluation of seven fracture models. Int J Mech Sci 2005;47:719-743.

[6] Alsos HS, Amdahl J. On the resistance of stiffened plates, Part I: Experiments. Int J Impact Eng 2009;36:799-807.

[7] Cho SR, Lee HS. Experimental and analytical investigations on the response of stiffened plates subjected to lateral collisions. Mar Struct 2009;22:84-95.

[8] Choung J, Cho SR, Kim KS. Impact test simulations of stiffened plates using the micromechanical porous plasticity model. Ocean Eng 2010;37:749-756.

[9] Gong AYF, Liu JX, Xiao BSM. Wang N. The analysis and comparison of double side skin crashworthiness. In: Proc. 6th International Conference on Collision and grounding of ships and offshore structures (ICCGS2013). Trondheim, Norway, 2013; p. 315-322.

[10] Villavicencio R, Liu B, Guedes Soares C. Experimental and numerical analysis of a tanker side panel laterally punched by a knife edge indenter. Mar Struct 2014;37:173-202.

[11] Liu B, Villavicencio R, Guedes Soares C. Simplified analytical method to evaluate tanker side panels during minor collision incidents. Int J Impact Eng 2015;78:20-33.

[12] Liu K, Wang Z, Tang W, Zhang Y, Wang G. Experimental and numerical analysis of laterally impacted stiffened plates considering the effect of strain rate. Ocean Eng 2015;99:44-54.

[13] Kim KJ, Lee JH, Park DK, Bo GJ, Xu H, Paik JK. An experimental and numerical study on nonlinear impact responses of steel-plated structures in an Arctic environment. Int J Impact Eng 2016;93:99-115.

[14] Gruben G, Solvernes S, Berstad T, Morin D, Hopperstad OS, Langseth M. Low-velocity impact behaviour and failure of stiffened steel plates. Mar Struct 2017;54:73-91.

[15] Kitamura O. Comparative study on collision resistance of side structure. Mar Technol 1997;34(4):293-308.

[16] Kitamura O, Kuroiwa T, Kawamoto Y, Kaneko E. A study on the improved tanker structure against collision and grounding damage. In: Proc. 7th International Symposium on Practical Design of Ships and Mobile Units (PRADS1998). The Hague, The Netherlands, 1998; p. 173179.

[17] Wolf M. Full scale collision experiment, X-type Sandwich side hull. EU Sandwich project report Deliverable TRD448, 2003; p. 21. 
[18] Liu J, Cui M, Zhang M. An experimental study on the resistance to penetration of hat-type stiffened plates. In: Proc. 7th International Conference on Collision and grounding of ships and offshore structures (ICCGS2016). Ulsan, Korea, 2016; p. 165-172.

[19] Yahiaoui M, Bracco M, Little P, Trauth AT. Experimental study on scale models for grounding. Joint MIT-Industry Program on Safe Tankers, Report 18. 1994.

[20] Kuroiwa T. Dynamic experiments and numerical simulations of failure of ship's side structure. In: Conference on prediction methodology of tanker structural failure and consequential oil spill, Japan; 1993. III1-7.

[21] Qvist S, Nielsen KB, Schmidt MH, Madsen SH. Ship collision- experimental and numerical analysis of double hull models. In: Proc. 9th Dymat Technical Conference Material and Structural Modelling in Collision Research. Munich, Germany, 1995.

[22] Simonsen BC, Ocakli H. Experiments and theory on deck and girder crushing. Thin Wall Struct 1999;34:195-216.

[23] Zhang S. The mechanics of ship collisions. Ph.D. thesis, Technical University of Denmark; 1999.

[24] Liu B, Guedes Soares C. Experimental and numerical analysis of the crushing behaviour of stiffened web girders. Int J Impact Eng 2016;88:22-38.

[25] Wierzbicki T. Concertina tearing of metal plates. Int J Solids Struct 1995; 32(19):2923-2943.

[26] Akita Y, Ando N, Fujita Y, Kitamura K. Studies on collision-protective structures in nuclear powered ships. Nucl Eng Des 1972; 19(2): 365-401.

[27] Woisin G. Design against collision. Schiff \& Hafen 1979; 31(2): 1059-1069, Germany.

[28] Ito H, Kondo K, Yoshimura N, Kawashima M, Yamamoto S. A simplified method to analyze the strength of double hulled structures in collision. Autumn Meeting Soc Naval Archit Japan 1984;158:420-434.

[29] Arita K, Aoki G. Strength of ship bottom in grounding (1 st report) - an investigation into the case of a ship stranded on a rock. J Soc Naval Archit Japan 1985;158:359-367.

[30] Amdahl J, Kavlie D. Experimental and numerical simulation of double hull stranding, in: DNV-MIT Workshop on Mechanics of Ship Collision and Grounding, DNV, Norway. 1992.

[31] Carlebur AFC. Full-scale collision tests. Saf Sci 1995;19:171-178.

[32] Wevers LJ, Vredeveldt AW. Full scale collision experiments 1998. TNO-report 98-CMCR1725, Netherlands 1999; p. 260.

[33] Paik JK, Chung JY, Choe IH, Thayamballi AK, Pedersen PT, Wang G. On rational design of double hull tanker structures against collision. Trans Soc Nav Archit Mar Eng 1999;107:323363.

[34] Wang G, Arita K, Liu D. Behavior of a double hull in a variety of stranding or collision scenarios. Mar Struct 2000;13:147-187.

[35] Peschmann J. Energy absorption computations of ship steel structures under collision and grounding (translated from German language), Ph.D. thesis, Technical University of Hamburg, 2001.

[36] Lehmann E, Peschmann J. Energy absorption by the steel structure of ships in the event of collisions. Mar Struct 2002;15:429-441.

[37] Karlsson UK, Ringsberg JW, Johnson E, HoseiniM, Ulfvarson A. Experimental and numerical investigation of bulb impact with a ship side-shell structure. Mar Technol 2009;46(1):16-26.

[38] Villavicencio R, Kim YH, Cho SR, Guedes Soares C. Deformation process of web girders in small-scale tanker double hull structures subjected to lateral impact. Mar Struct 2013;32:84112.

[39] Tautz I, Schotelndreyer M, Lehmann E, Fricke W. Collision tests with rigid and deformable bulbous bows driven against double hull side structures. In: Proc. 6th International Conference on Collision and grounding of ships and offshore structures (ICCGS2013). Trondheim, Norway, 2013. p. 93-100.

[40] Lu G, Calladine CR. On the cutting of a plate by a wedge. Int J Mech Sci 1990;32(4):293-313. 
[41] Jones N, Jouri WS. A study of plate tearing for ship collision and grounding damage. J Ship Res 1987;31(4):253-268.

[42] Thomas PF. Application of plate cutting mechanics to damage prediction in ship grounding. Joint MIT-industry program on tanker safety. 1992. Report no. 8.

[43] Astrup O. Cutting of thick plates by a wedge - an experimental study. Joint MIT-industry program on tanker safety. 1994. Report no. 27.

[44] Paik JK. Cutting of a longitudinally stiffened plate by a wedge. J Ship Res 1994;38(4):340348.

[45] Kuroiwa T, Kawamoto Y, Yuhara T. Study on damage of ship bottom structures due to grounding. In: Conference on prediction methodology of tanker structural failure and consequential oil spill, Japan; 1993. p. III39-47.

[46] Shen WQ, Fung KW, Triantafyllos P, Wajid NM, Nordin N. An experimental study on the scaling of plate cutting. Int J Impact Eng 1998;21(8):645-662.

[47] Simonsen BC, Tornqvist R. Experimental and numerical modelling of ductile crack propagation in large-scale shell structures. Mar Struct 2004;17:1-27.

[48] Rodd JL. Observations on conventional and advanced double hull grounding experiments. In: International conference on designs and methodologies for collision and grounding protection of ships, San Francisco, USA, 1996. p. 13.1-13.13.

[49] Sterndorff MJ, Pedersen PT. Grounding experiments on soft bottoms. J Mar Sci Technol 1996;1:174-181.

[50] Vredeveldt AW, Wevers LT. Full scale grounding experiments. In: Conference on prediction methodology of tanker structural failure and consequential oil spill, Tokyo, Japan; 1995.

[51] Calle MAG, Oshiro RE, Alves M. Ship collision and grounding: Scaled experiments and numerical analysis. Int J Impact Eng 2017;103:195-210.

[52] Hayduk RJ, Wierzbicki T. Extensional collapse modes of structural members. Comput Struct 1984;18(3):447-458.

[53] Jones N, Birch RS. Dynamic and static axial crushing of axially stiffened square tubes. Proc Instn Mech Engrs 1990;204(C):293-310.

[54] Paik JK, Chung JY, Chun MS. On quasi-static crushing of a stiffened square tube. J Ship Res 1996;40(3):31-60.

[55] Abramowicz W, Simonsen BC. Effect of Fracture on Crushing of Ship Structures. J Ship Res 2003;47(3):194-207.

[56] Amdahl J. Energy absorption in ship-platform impacts. Ph.D. Thesis, Norwegian University of Science and Technology, Trondheim, Norway; 1983.

[57] Hagiwara K, Takanabe H, Kawano H. A proposed method of predicting ship collision damage. Int. J Impact Eng 1983; 1(3):257-279.

[58] Endo H, Yamada Y, Kitamura O, Suzuki K. Model test on the collapse strength of the buffer bow structures. Mar Struct 2002;15:365-381.

[59] Yamada Y, Endo H. Collapse mechanism of the buffer bow structure on axial crushing. Int J Offshore Polar Eng 2005;15(2):147-154.

[60] Yamada Y. Bulbous buffer bows: a measure to reduce oil spill in tanker collisions. Ph.D. thesis, Technical University of Denmark; 2006.

[61] Yamada Y, Endo H. Experimental and numerical study on the collapse strength of the bulbous bow structure in oblique collision. Mar Technol 2008;45(1):42-53.

[62] Tautz I, Schotelndreyer M, Fricke W, Lehmann E. Experimental investigations on collision behaviour of bow structures. In: Proc. 5th International Conference on Collision and grounding of ships (ICCGS2010). Espoo, Finland, 2010; p. 179-183.

[63] Liu B, Guedes Soares C. Simplified analytical method for evaluating web girder crushing during ship collision and grounding. Mar Struct 2015;42:71-94.

[64] Hong L. Simplified analysis and design of ships subjected to collision and grounding. Ph.D. thesis, Norwegian University of Science and Technology; 2008.

[65] Jones N. Structural Impact (2nd edition). New York, USA: Cambridge University Press; 2012. 
[66] Oshiro RE, Calle MAG, Mazzariol LM, Alves M. Experimental study of collision in scaled naval structures. Int J Impact Eng 2017; DOI: 10.1016/j.ijimpeng.2017.01.024.

[67] Wen HM, Jones N. Experimental investigation of the scaling laws for metal plates struck by large masses. Int J Impact Eng 1993;13(3):485-505.

[68] Wang G. Structural analysis of ships' collision and grounding. Ph.D. thesis, University of Tokyo; 1995.

[69] Wang G. Some recent studies on plastic behavior of plates subjected to large impact loads. J Offshore Mech Arctic Eng 2002;124:125-131.

[70] Haris S, Amdahl J. An analytical model to assess a ship side during a collision. Ships Offshore Struct 2012;7(4):431-448.

[71] Simonsen BC, Lauridsen LP. Energy absorption and ductile failure in metal sheets under lateral indentation by a sphere. Int J Impact Eng 2000;24:1017-1039.

[72] Lee YW, Woertz JC, Wierzbicki T. Fracture prediction of thin plates under hemi-spherical punch with calibration and experimental verification. Int J Mech Sci 2004;46:751-781.

[73] Jones N, Birch RS, Duan R. Low-velocity perforation of mild steel rectangular plates with projectiles having different shaped impact faces. J Press Vess Technol 2008;130(3): 031206.

[74] Jones N, Paik JK. Impact perforation of aluminium alloy plates. Int J Impact Eng 2012;48:4653.

[75] Jones N, Paik JK. Impact perforation of steel plates. Ships Offshore Struct 2013;8(5):579-596.

[76] Liu B, Villavicencio R, Guedes Soares C. On the failure criterion of aluminium and steel plates subjected to low-velocity impact by a spherical indenter. Int J Mech Sci 2014;80:1-15.

[77] Liu B, Villavicencio R, Guedes Soares C. Simplified method for quasi-static collision assessment of a damaged tanker side panel. Mar Struct 2015;40:267-288.

[78] Yang PDC, Caldwell JB. Collision energy absorption of ship’s bow structures. Int J Impact Eng 1988;7(2):181-96.

[79] Santosa S, Wierzbicki T. On the modeling of crush behavior of closed-cell aluminum foam structure. J Mech Phys Solids 1998;46(4):645-669.

[80] Wierzbicki T, Driscoll JC. Crushing damage of web girders under localized static loads. J Constr Steel Res 1995;33:199-235.

[81] Hong L, Amdahl J. Crushing resistance of web girders in ship collision and grounding. Mar Struct 2008;21:374-401.

[82] Liu B, Guedes Soares C. Analytical method to determine the crushing behaviour of girders with stiffened web. Int J Impact Eng 2012;93:49-61.

[83] Haris S, Amdahl J. Crushing resistance of a cruciform and its application to ship collision and grounding. Ships Offshore Struct 2012;7(2):185-195.

[84] Liu B, Villavicencio R, Zhang S, Guedes Soares C. A simple criterion to evaluate the rupture of materials in ship collision simulations. Mar Struct 2017;54:92-111.

[85] Liu B, Guedes Soares C. Assessment of the strength of double-hull tanker side structures in minor ship collisions. Eng Struct 2016;120:1-12.

[86] Wang G, Ohtsubo H, Liu D. A simple method for predicting the grounding strength of ships. J Ship Res 1997;41(3):241-247.

[87] Simonsen BC. Ship grounding on rock - I. Theory. Mar Struct 1997;10:519-562.

[88] Simonsen BC. Ship grounding on rock: II validation and application. Mar Struct 1997;10:56384.

[89] Zhu L, James P, Zhang S. Statistics and damage assessment of ship grounding. Mar Struct 2002;15:515-530.

[90] Heinvee M, Tabri K, Korgesaar M. A simplified approach to predict the bottom damage in tanker grounding. In: Proc. 6th International Conference on Collision and grounding of ships and offshore structures (ICCGS2013). Trondheim, Norway, 2013. p. 161-169.

[91] Wierzbicki T, Thomas P. Closed-form solution for wedge cutting force through thin metal sheets. Int J Mech Sci 1993;35 (3/4):209-229. 
[92] Ohtsubo H, Wang G. An upper-bound solution to the problem of plate tearing. J Mar Sci Technol 1995;1:46-51.

[93] Zhang S. Plate tearing and bottom damage in ship grounding. Mar Struct 2002;15:101-117.

[94] Simonsen BC, Tornqvist R, Lutzen M. A simplified grounding damage prediction method and its application in modern damage stability requirements. Mar Struct 2009;22:62-83.

[95] Hong L, Amdahl J. Rapid assessment of ship grounding over large contact surfaces. Ships Offshore Struct 2012;7(1):5-19.

[96] Hong L, Amdahl J. Plastic mechanism analysis of the resistance of ship longitudinal girders during grounding and collision. Ships Offshore Struct 2008;3(3):159-171.

[97] Yu Z, Hu Z, Amdahl J, Liu Y. Investigation on structural performance predictions of doublebottom tankers during shoal grounding accidents. Mar Struct 2013;33(10):188-213.

[98] Wierzbicki T, Abramowicz W. On the crushing mechanics of thin-walled structures. J Appl Mech 1983;50:727-734.

[99] Pedersen PT, Valsgaard S, Olsen D, Spangenberg S. Ship impacts: bow collisions. Int J Impact Eng 1993;13(2):163-187.

[100] Abramowicz W. Crush resistance of T, Y and X sections. Joint MIT-industry program on tanker safety. 1994. Report no. 24.

[101] Paik JK, Pedersen PT. Ultimate and crushing strength of plated structures. J Ship Res 1995;39(3):250-261.

[102] Paik JK, Wierzbicki T. A benchmark study on crushing and cutting of plated structures. J Ship Res 1997;41(2):147-160.

[103] Zhang S, Ocakli H, Pedersen PT. Crushing of ship bows in head-on collision. Int J Marit Eng 2004;146(2):39-46.

[104] Yamada Y, Pedersen P. A benchmark study of procedures for analysis of axial crushing of bulbous bows. Mar Struct 2008;21(2-3):257-293.

[105] Minorsky VU. An analysis of ship collision with reference to protection of nuclear power ships. J Ship Res. 1959;3(2):1-4.

[106] Pedersen PT, Zhang S. Absorbed energy in ship collisions and grounding - revising Minorsky’s empirical method. J Ship Res. 2000;44(2):140-154.

[107] Lloyd's Register. Guidance notes for collision assessment for the location of low-flashpoint fuel tanks; 2016.

[108] Dieter GE. Mechanical behavior under tensile and compressive loads. ASM Handbook 2000;8:237-415.

[109] Johnson GR, Cook WH. A constitutive model and data for metals subjected to large strains, high strain rates and high temperatures. In: Proceedings of the seventh international symposium on ballistics, The Hague. 1983.

[110] Alsos HS, Hopperstad OS, Tornqvist R, Amdahl J. Analytical and numerical analysis of sheet metal instability using a stress based criterion. Int J Solids Struct 2008;45:2042-2055.

[111] Ehlers S. The influence of the material relation on the accuracy of collision simulations. Mar Struct 2010;23:462-474.

[112] Villavicencio R, Guedes Soares C. Numerical plastic response and failure of a pre-notched transversely impacted beam. Ships Offshore Struct 2012;7(4):417-429.

[113] Liu B, Villavicencio R, Guedes Soares C. Experimental and numerical plastic response and failure of laterally impacted rectangular plates. J Offshore Mech Arctic Eng 2013;135(4):041602.

[114] Ehlers S, Varsta P. Strain and stress relation for non-linear finite element simulations. Thin Wall Struct 2009;47:1203-1217.

[115] Ehlers S. Strain and stress relation until fracture for finite element simulations of a thin circular plate. Thin Wall Struct 2010;48(1):1-8.

[116] Jones N. The credibility of predictions for structural designs subjected to large dynamic loadings causing inelastic behaviour. Int J Impact Eng 2013;53:106-114. 
[117] Storheim M, Amdahl J. On the sensitivity to work hardening and strain rate effects in nonlinear FEM analysis of ship collisions. Ships Offshore Struct 2017;12(1):100-115.

[118] American Society for Testing and Materials (ASTM). Standard methods of tension testing of metallic materials, E 8.

[119] Calle MAG, Alves M. A review-analysis on material failure modeling in ship collision. Ocean Eng 2015;106(1):20-38.

[120] Zhang L, Egge ED, Bruhns H. Approval procedure concept for alternative arrangements. In. Proc. 3rd International Conference on Collision and Grounding of Ships: Izu, Japan 2004; p. 87-96.

[121] Törnqvist R. Design of crashworthy ship structures, Ph.D. thesis, Technical University of Denmark, 2003.

[122] Alsos HS, Hopperstad OS, Törnqvist R, Amdahl J. Analytical and numerical analysis of sheet metal instability using a stress based criterion. Int J Solids Struct 2008;45:2042-2055.

[123] Storheim M, Alsos H, Hopperstad OS, Amdahl J. A damage-based failure model for coarsly meshed shell structures. Int J Impact Eng 2015;83:59-75.

[124] Ehlers S, Broekhuijsen J, Alsos HS, Biehl F, Tabri K. Simulating the collision response of ship structures: A failure criteria benchmark study. Int Shipbuild Prog 2008;55:127-144.

[125] Storheim M, Amdahl J, Martens I. On the accuracy of fracture estimation in collision analysis of ship and offshore structures. Mar Struct 2015;44:254-287.

[126] Marinatos J, Samuelides M. Towards a unified methodology for the simulation of rupture in collision and grounding of ships. Mar Struct 2015;42:1-32.

[127] Jones N. Influence of in-plane displacements at the boundaries of rigid-plastic beams and plates. Int J Mech Sci 1973;15:547-561.

[128] Villavicencio R, Guedes Soares C. Numerical modelling of laterally impacted plates reinforced by free and end connected stiffeners. Eng Struct 2012;44:46-62.

[129] Liu B, Villavicencio R, Guedes Soares C. Experimental and numerical plastic response and failure of pre-notched transversely impacted beams. Int J Mech Sci 2013;77:314-332.

[130] Alsos HS, Amdahl J, Hopperstad O. On the resistance of stiffened plates, Part II: Numerical analysis. Int J Impact Eng 2009;36:875-887.

[131] Hu Z, Amdahl J, Hong L. Verification of a simplified analytical method for predictions of ship groundings over large contact surfaces by numerical simulations. Mar Struct 2011;24:436-458.

[132] Nguyen TH, Amdahl J, Leira BJ, Garrè L. Understanding ship-grounding events. Mar Struct 2011;24:551-569.

[133] Haris S, Amdahl J. Analysis of ship-ship collision damage accounting for bow and side deformation interaction. Mar Struct 2013;32:18-48. 


\section{Tables and figures}

Table 1: Available methods for structural impacts.

\begin{tabular}{lccccc}
\hline Method & \multicolumn{2}{c}{ Analysis } & & \multicolumn{2}{c}{ Result } \\
\cline { 2 - 6 } & Effort & Difficulty & Energy & Load & Stress \\
\hline Experiment & Expensive, time consuming & Scaling effect & $\mathrm{X}$ & $\mathrm{X}$ & $\mathrm{X}$ \\
Empirical formula & Hand calculation & Lack validation & $\mathrm{X}$ & & \\
Analytical formula & Hand calculation & Lack validation & $\mathrm{X}$ & $\mathrm{X}$ & $\mathrm{X}$ \\
Numerical simulation & Specialty, time consuming & Definition of material fracture & $\mathrm{X}$ & $\mathrm{X}$ \\
\hline
\end{tabular}

Table 2: Internal mechanics in ship collisions and grounding.

\begin{tabular}{lcccc}
\hline Scenario & \multicolumn{4}{c}{ Main failure mode of plate elements } \\
\cline { 2 - 4 } & Tension & Folding/Crushing & Tearing/Cutting & Sliding \\
\hline Side collision & $\mathrm{X}$ & $\mathrm{X}$ & \\
Bow collision & & $\mathrm{X}$ & & \\
Stranding & $\mathrm{X}$ & $\mathrm{X}$ & $\mathrm{X}$ & $\mathrm{X}$ \\
Raking & & $\mathrm{X}$ & \\
\hline
\end{tabular}

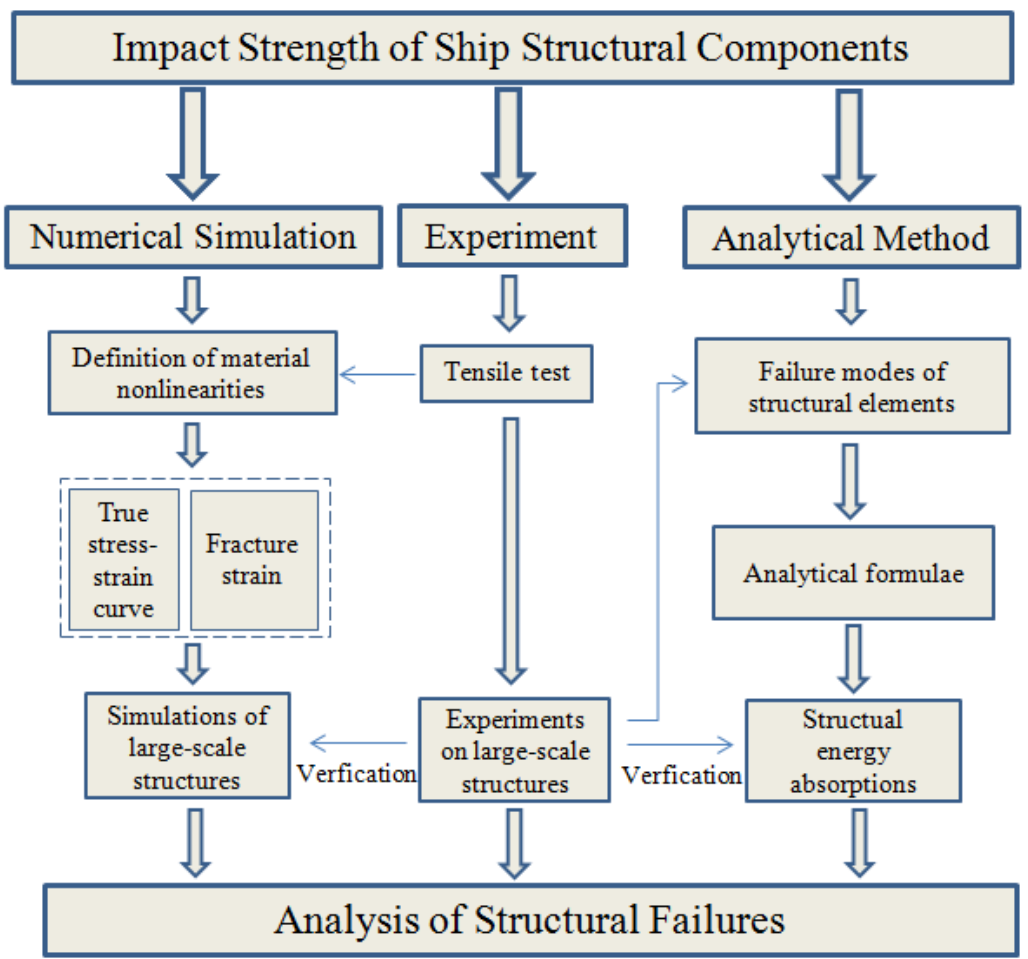

Fig 1: Analysis procedure of impact strength of ship structural components. 
a

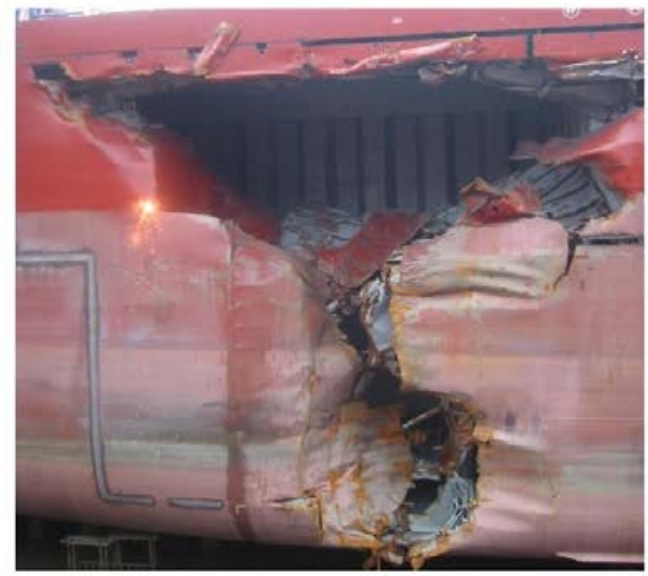

b

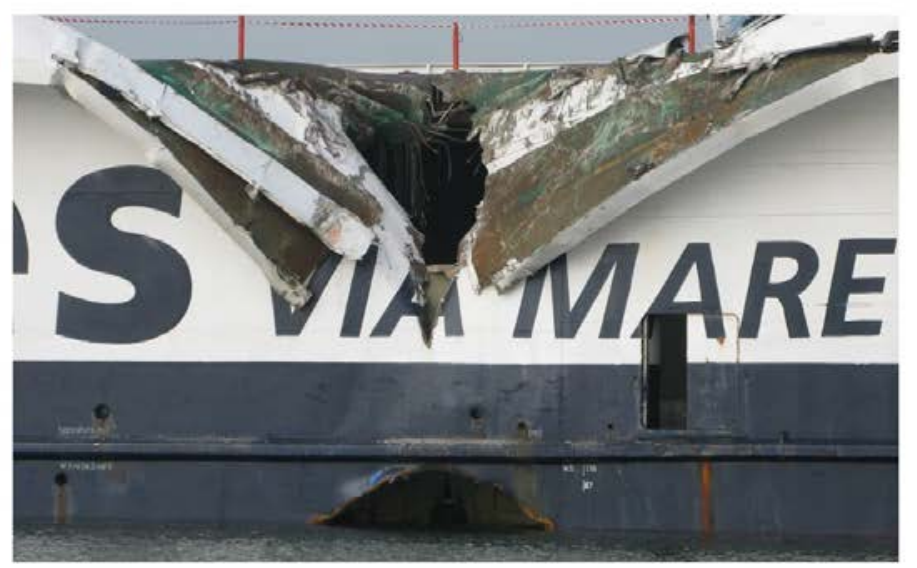

Fig 2: Collision damage to (a) an oil tanker and (b) an RoPax ship; cf. Refs. [3, 4].
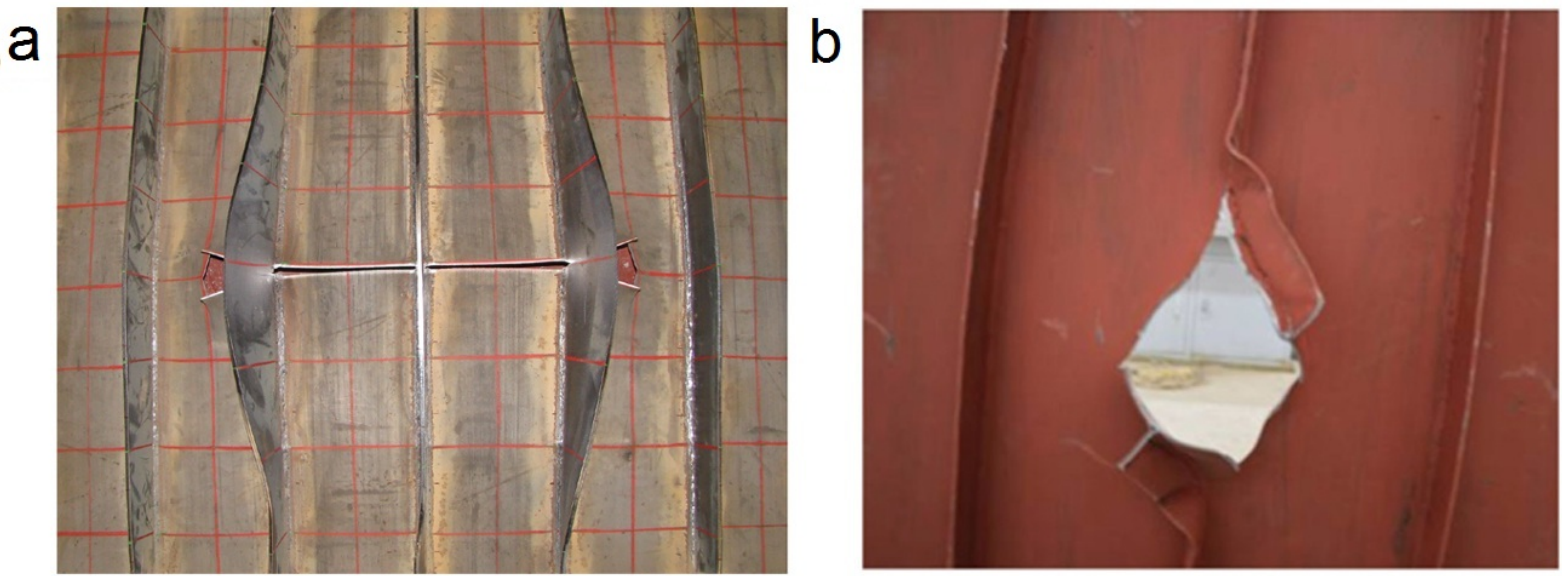

Fig 3: Failure modes of stiffened panels subjected to (a) a wedge and (b) a hemispherical indenter, respectively; cf. Refs. [10, 12].

a
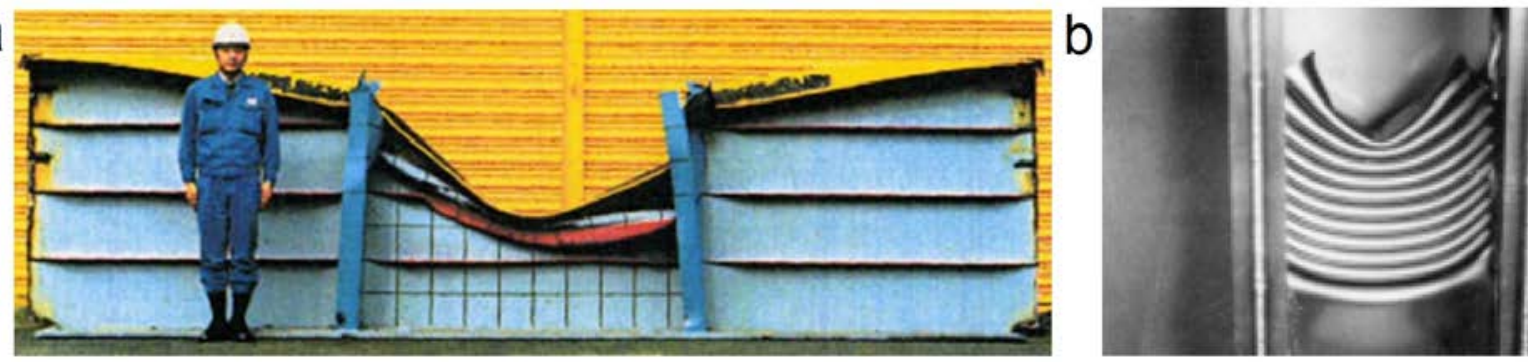

Fig 4: (a) Folding and (b) concertina tearing of web girders under local in-plane loads; cf. Refs. [19, 20]. 


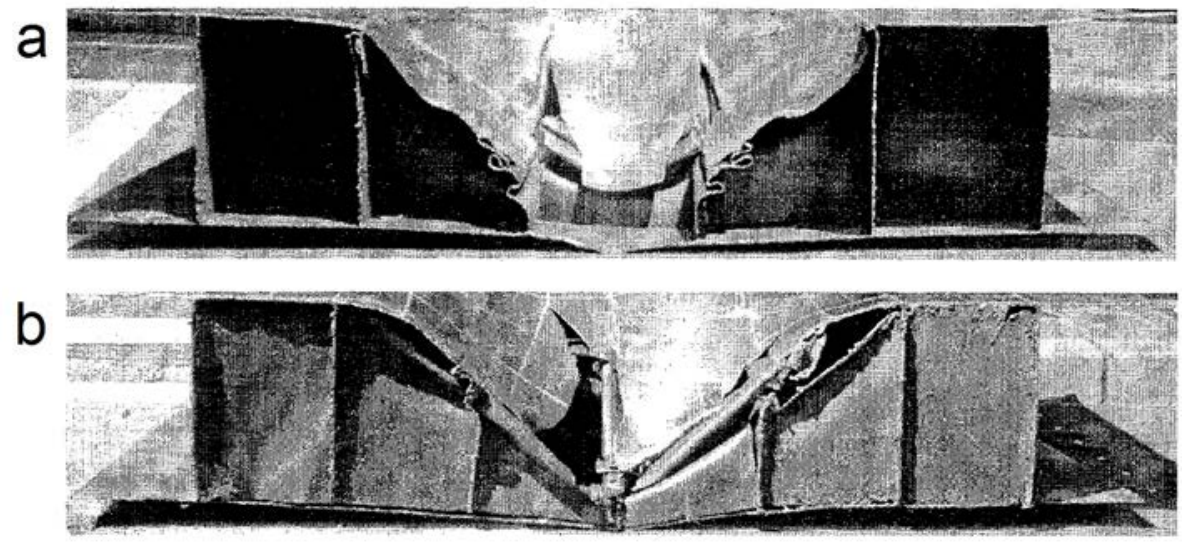

Fig 5: Failure modes of double-hull structures loading at (a) a bare plate and (b) a plate intersection. The structures are cut along the centre line after testing; cf. Ref. [33].
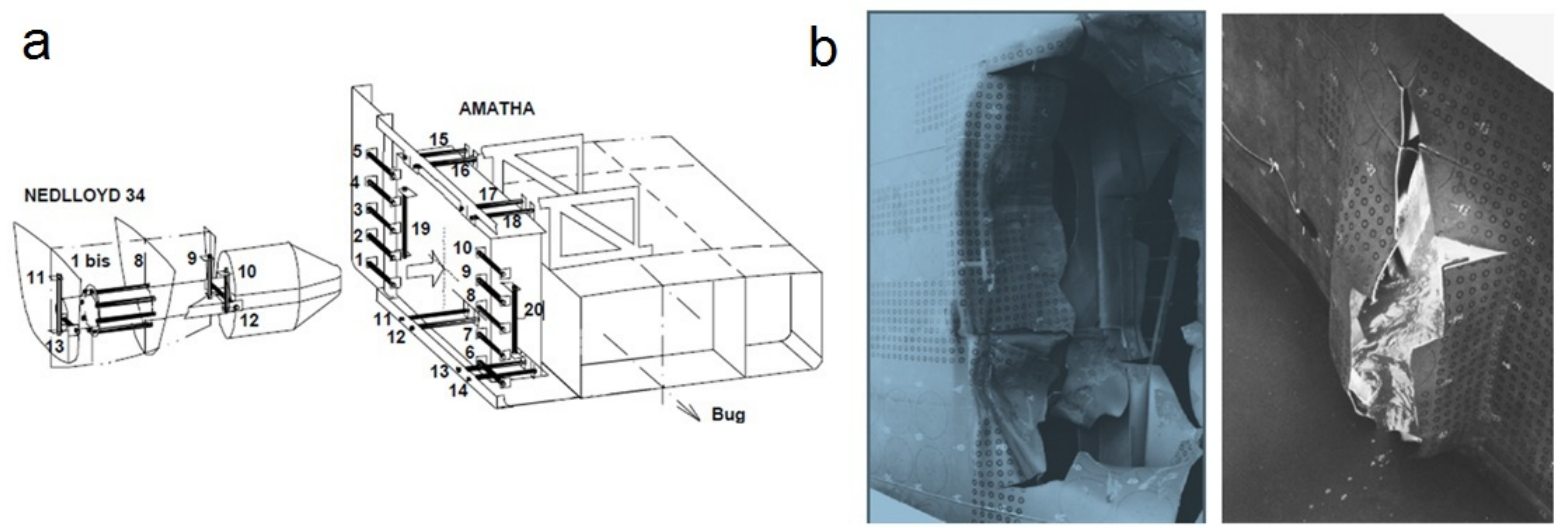

Fig 6: (a) Supporting of the bow and the test section and (b) failure mode of the double-hull structure under bulbous bow collision; cf. Ref. [35].
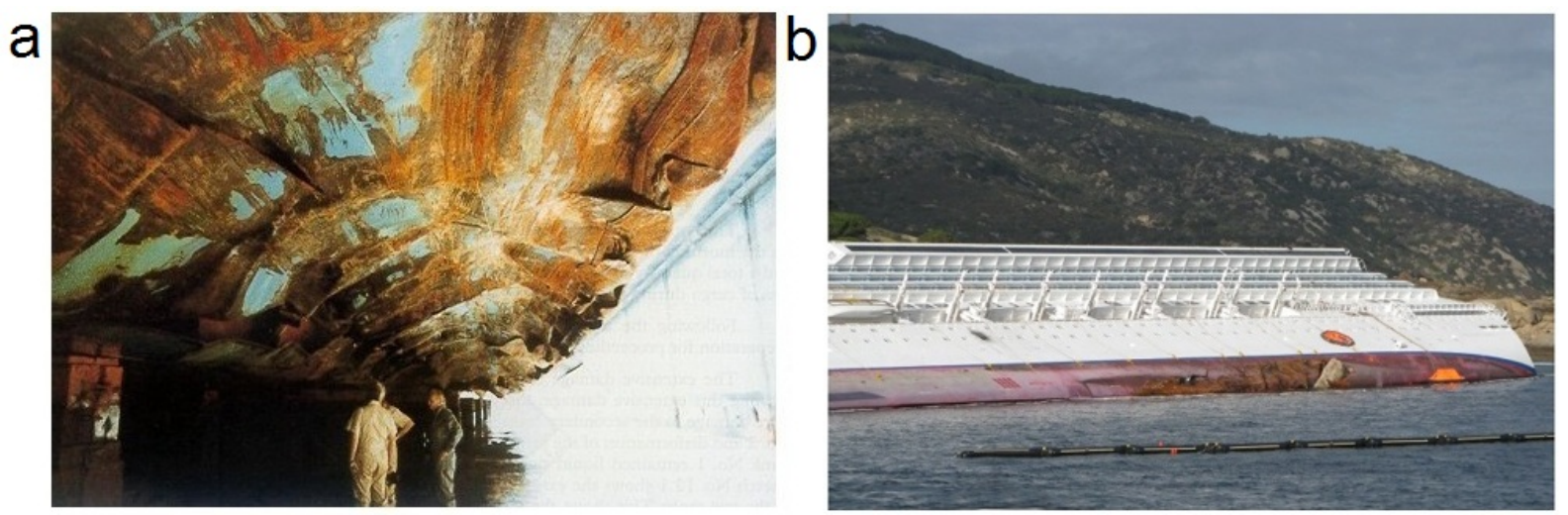

Fig 7: Failure modes of ship bottoms in raking. (a) an LNG carrier in dry dock after grounding; cf. Ref. [64]. (b) In 2012 the cruise vessel Costa Concordia hit an underwater rock near the cost in Northern Italy. The contact resulted in a gash $4 \mathrm{~m}$ below the waterline. 


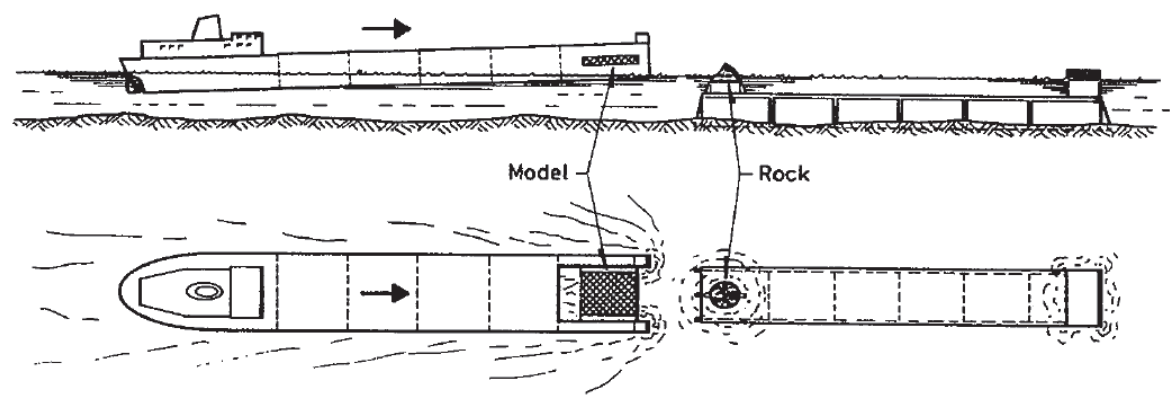

Fig 8: ASIS bottom raking test setup; cf. Ref. [50].
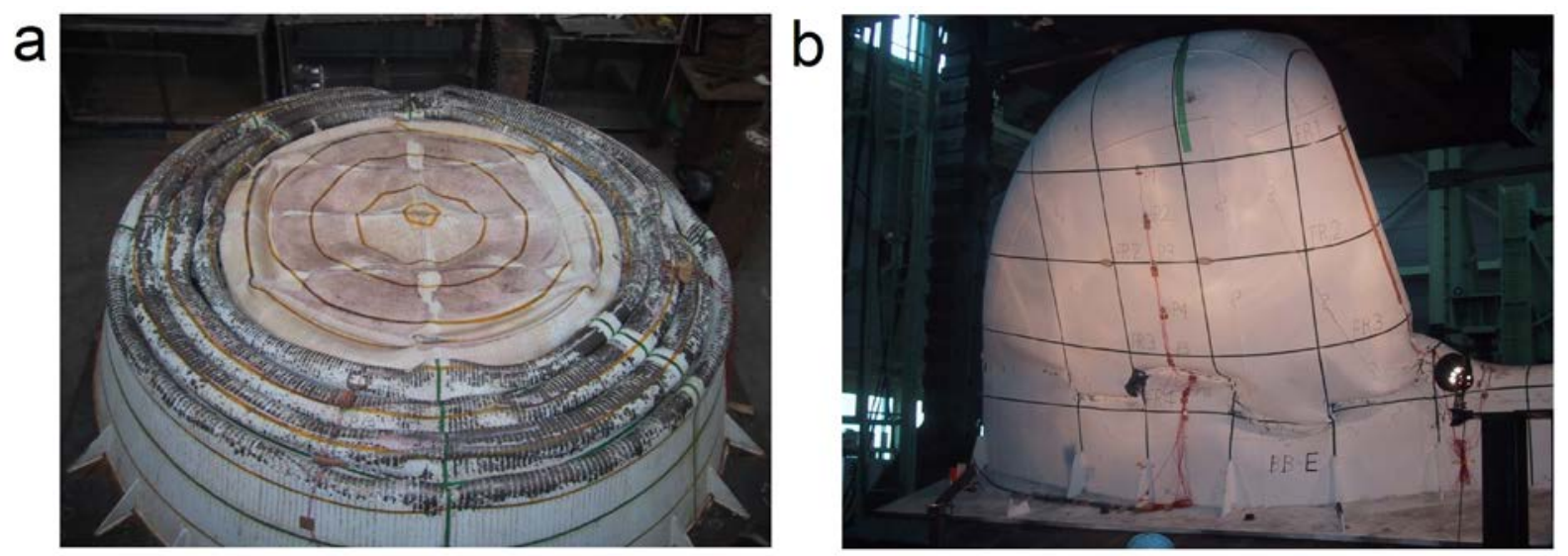

Fig 9: Deformation of bow model after collapse experiments; cf. Ref. [60].
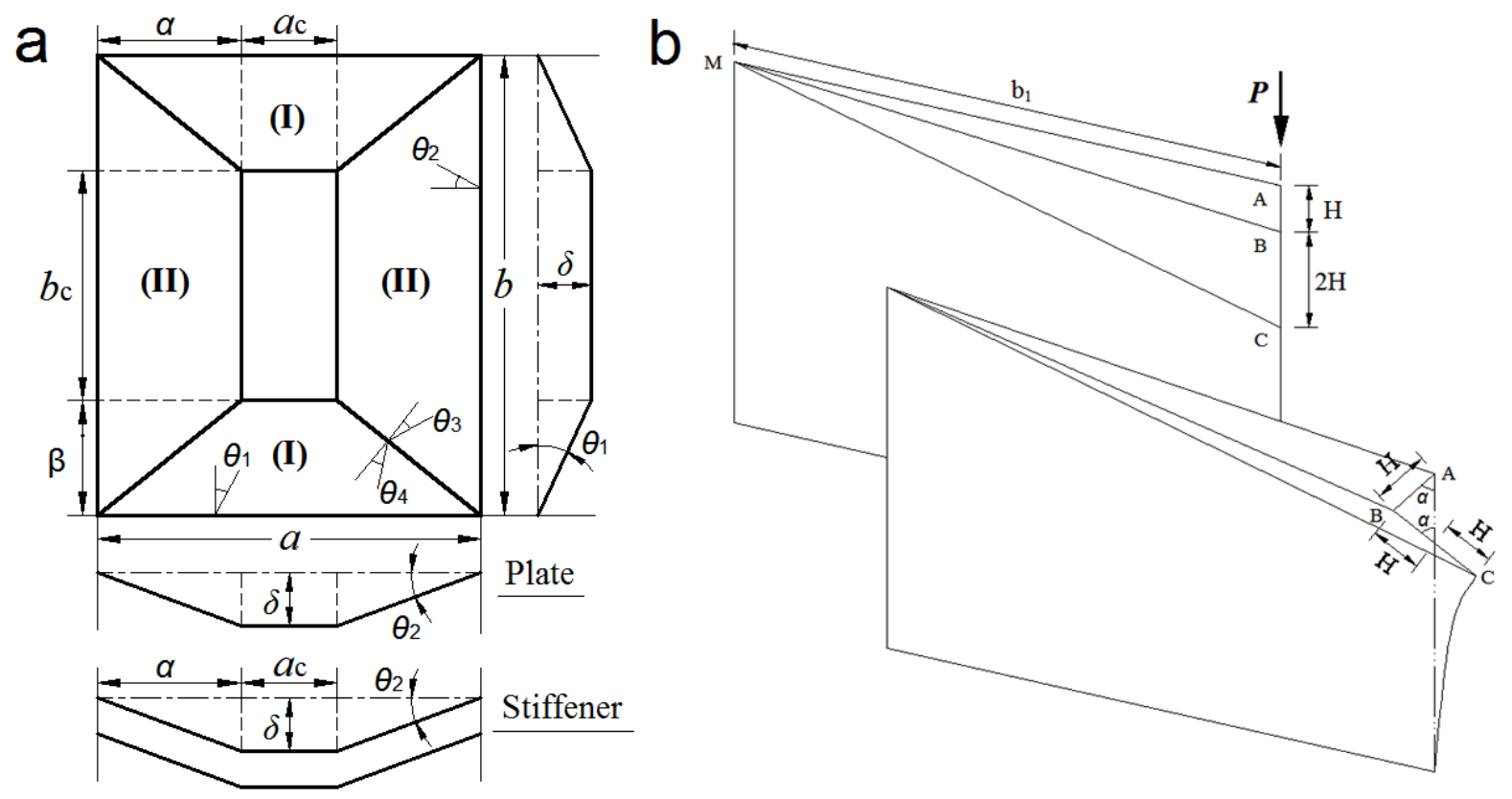

Fig 10: Assumed deformed shape of (a) stiffened plate and (b) web girder that undergo plastic deformation; cf. Refs. [11, 63]. 


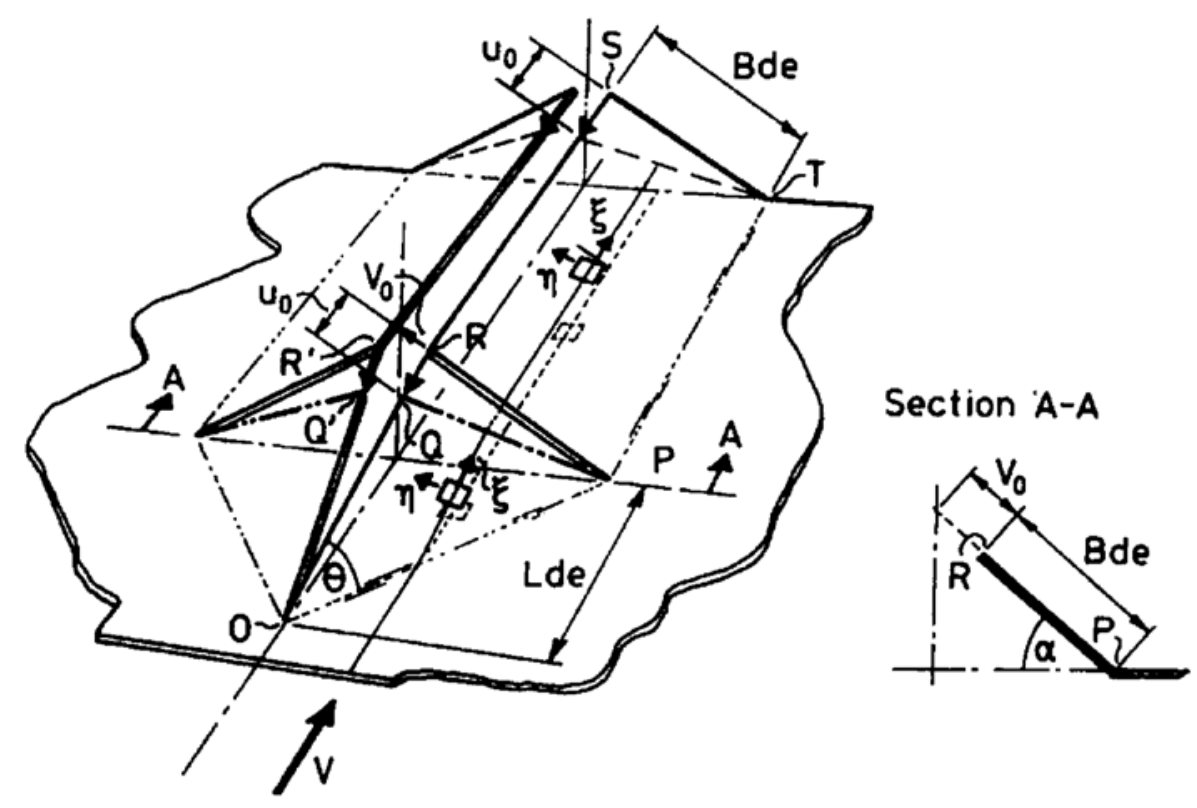

Fig 11: Assumed deformation mode of bottom plate in raking; cf. Ref. [87].
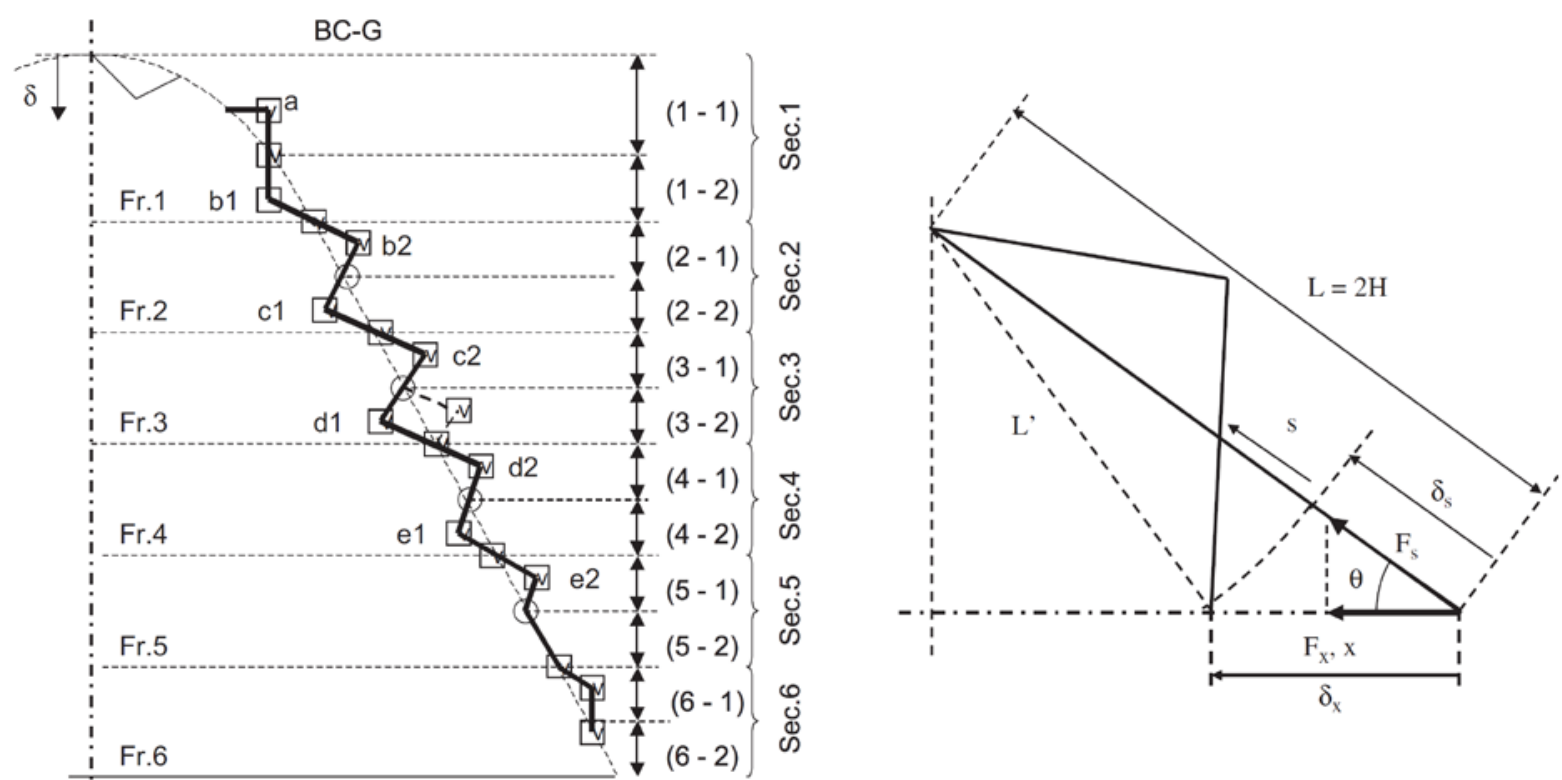

Fr.: frame number, Sec.: section, (1-1)-(6-2): sub-section square : plastic hinge, $\delta$ : displacement of rigid plate

Fig 12: Assumed deformation mode of bulbous bow under crushing; cf. Ref. [104]. 


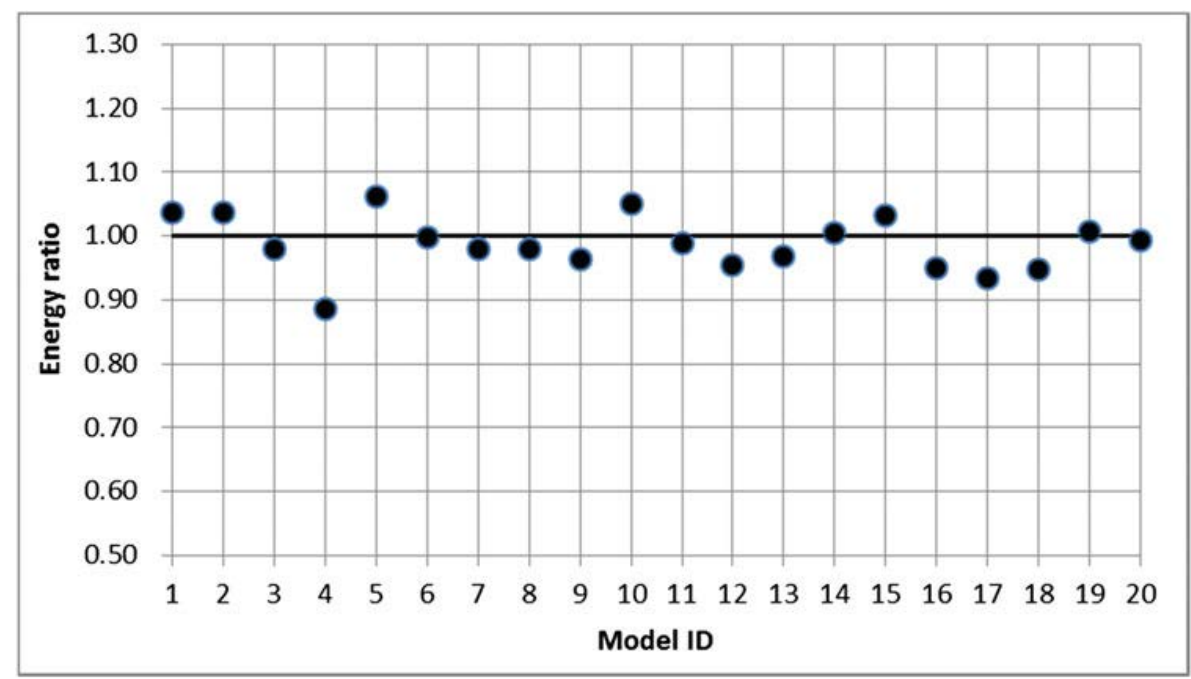

Fig 13: Semi-analytical methods calculated energy normalised with experimental result for twenty model tests; cf. Ref. [3].

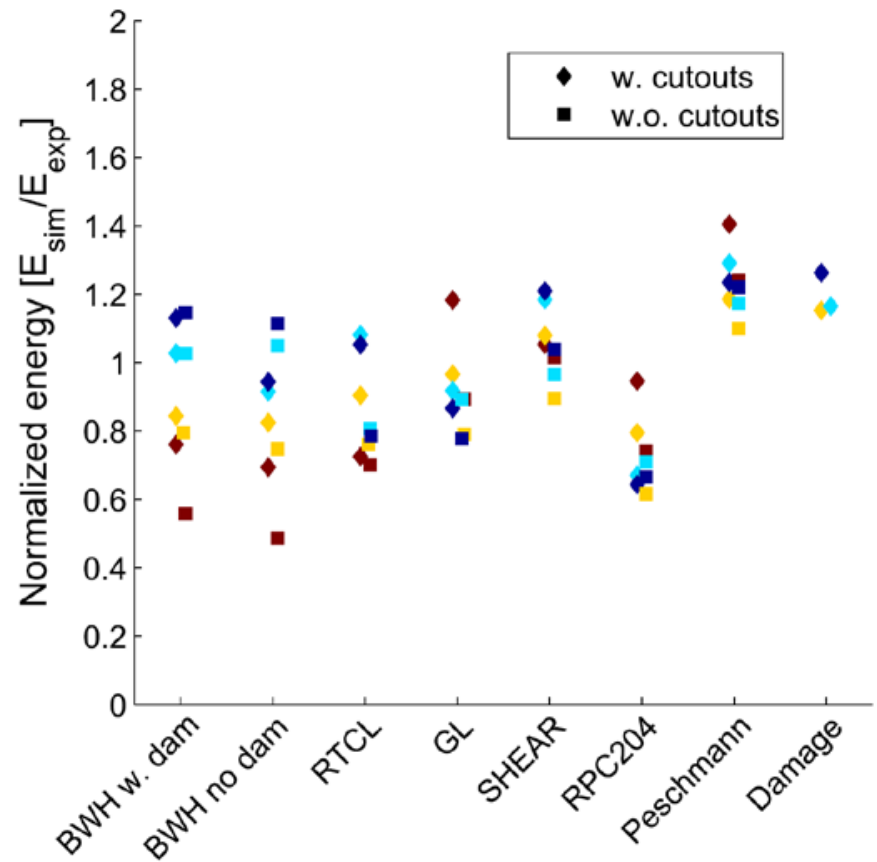

Fig 14: Finite element results on collision energy normalised with the experimental results at the final structural penetrations using different failure criteria with various mesh sizes; cf. Ref. [125]. 


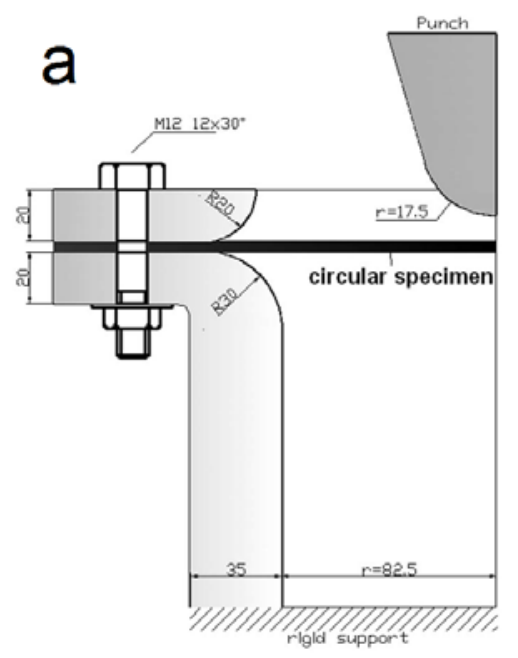

b
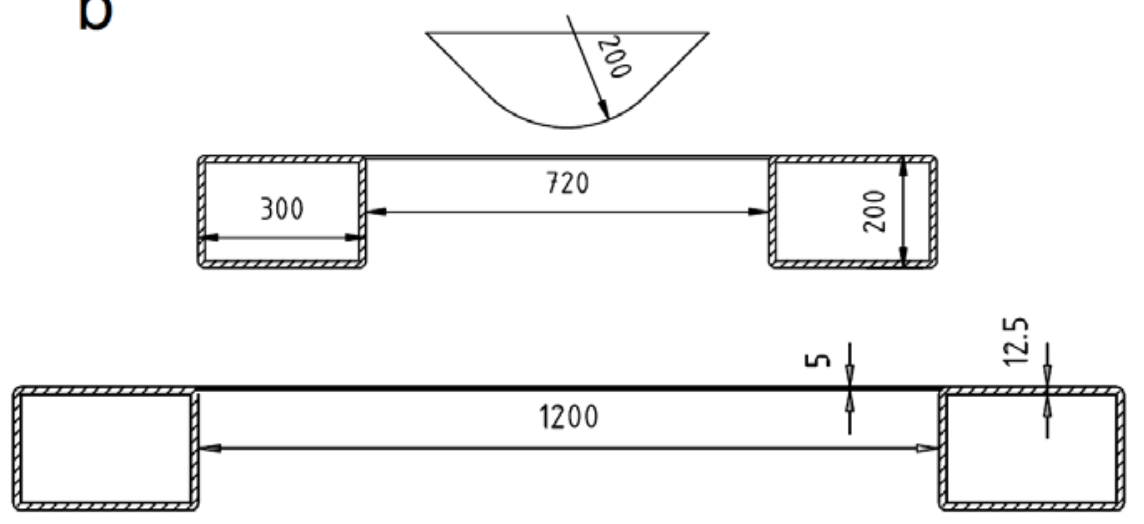

Fig 15: Specimens (a) clamped by bolts and (b) welded on rectangular cross-section tubes; cf. Refs. $[6,115]$.
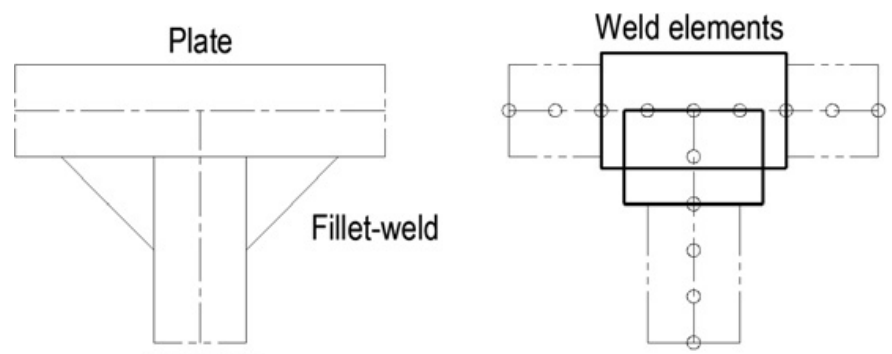

Stiffener

Fig 16: Weld elements of the plate-stiffener intersection; cf. Ref. [128].

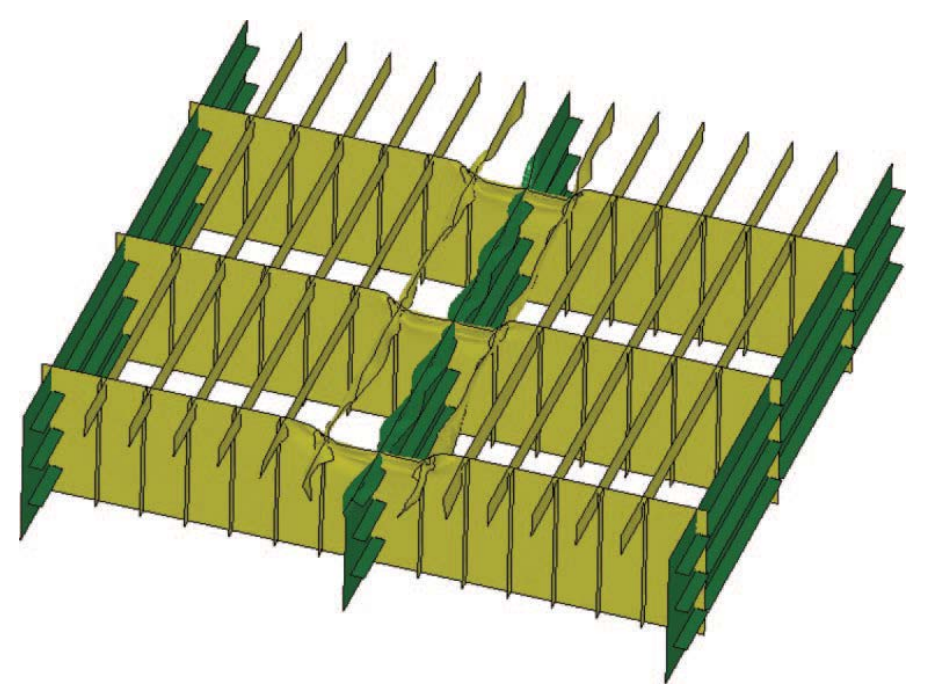

Fig 17: The deformation of the bottom structure after grounding; cf. Ref. [95]. 